\title{
Correction to: Declining Sexual Activity and Desire in Women: Findings from Representative German Surveys 2005 and 2016
}

\author{
Juliane Burghardt $^{1}{ }^{\oplus} \cdot$ Manfred E. Beutel $^{1} \cdot$ Annette Hasenburg $^{2} \cdot$ Gabriele Schmutzer $^{3} \cdot$ Elmar Brähler $^{1}$
}

Published online: 2 January 2020

(c) Springer Science+Business Media, LLC, part of Springer Nature 2020

Correction to: Archives of Sexual Behavior https://doi.org/10.1007/s10508-019-01525-9

As a result of a typesetting error, the number of participants in the study reported in this article was incorrectly stated in the article's Abstract as originally published.

The correct number of participants is 1345 (rather than 345 , as originally stated).

The original article has been corrected.

Publisher's Note Springer Nature remains neutral with regard to jurisdictional claims in published maps and institutional affiliations.

The original article can be found online at https://doi.org/10.1007/ s10508-019-01525-9.

Juliane Burghardt

JBurghardt@ucdavis.edu

1 Department of Psychosomatic Medicine and Psychotherapy,

University Medical Center Mainz of the Johannes Gutenberg

University Mainz, Untere Zahlbacher Str. 8, 55131 Mainz,

Germany

2 Department of Obstetrics and Gynecology, University

Medical Center Mainz of the Johannes Gutenberg University

Mainz, Mainz, Germany

3 Selbständige Abteilung für Medizinische Psychologie,

Universität Leipzig, Leipzig, Germany 